\title{
EXERCÍCIO DA FUNÇÃO INSTRUMENTAL PELO PODER JUDICIÁRIO NOS ESTADOS LIBERAL E SOCIAL: BREVES ANOTAÇÕES
}

\author{
Wermeson Pinheiro Barbosa ${ }^{1}$ \\ Edith Maria Barbosa Ramos ${ }^{2}$
}

\section{RESUMO}

Objetivou-se reconstruir, partindo-se do Estado Moderno, o processo difuso de atribuição de funções ao Poder Judiciário, para demonstrar que referido Poder, ao longo dos anos, sofreu uma reconfiguração no conjunto de suas funções institucionais cujo resultado culminou no fortalecimento de sua função política, representada pelo controle de constitucionalidade e autogoverno, assim como demarcou a crise de sua função instrumental, caracterizada pela inefetividade na resolução dos conflitos de interesses. Utilizou-se o método descritivo exploratório com revisão bibliográfica para se chegar à consideração de que ainda hoje é obtusa a discussão sobre a extensão e profundidade das funções exercidas pelo Poder Judiciário. Palavras-chave: Poder Instrumental. Poder Judiciário. Estado liberal. Estado social.

\section{EXERCISE OF THE INSTRUMENTAL FUNCTION BY THE JUDICIARY POWER IN THE LIBERAL AND SOCIAL STATES: SHORT NOTES}

\begin{abstract}
The purpose of this study was to reconstruct the diffuse process of assigning functions to the Judiciary Branch, starting from the Modern State, in order to demonstrate that, over the years, this power has undergone a reconfiguration in its institutional functions, the result of which has resulted in the strengthening of its political function, represented by the control of constitutionality and self-government, as well as demarcated the crisis of its instrumental function, characterized by the ineffectiveness of the resolution of conflicts of interest. The exploratory descriptive method with bibliographical revision was used to arrive at the consideration that still today is obtuse the discussion about the extent and depth of the functions exercised by the Judiciary.
\end{abstract}

Key words: Instrumental Power. Judicial power. Liberal state. Social status.

\footnotetext{
${ }^{1}$ Mestre em Direito pelo Programa de Pós-graduação stricto sensu em Direito e Instituições do Sistema de Justiça da Universidade Federal do Maranhão. Mestre Profissional em Ciências Policiais de Segurança e Ordem Pública pelo Centro de Altos Estudos de Segurança Pública da Polícia Militar de São Paulo. Especialista em Ciências Criminais pela Universidade Anhanguera. Graduado em Segurança Pública pela Universidade Estadual do Maranhão. Graduado em Direito pela Universidade Federal do Maranhão. Major da Polícia Militar do Maranhão com experiência na área da Segurança Pública e em Direito, com ênfase em Direito Constitucional, Penal e Processual Penal.

2 Pós-Doutora em Direito Sanitário pela Fundação Oswaldo Cruz - FIOCRUZ/Brasília/DF. Doutora em Políticas Públicas pela Universidade Federal do Maranhão. Mestre em Direito pela Universidade Federal de Minas Gerais. Graduada em Direito pela Universidade Federal do Maranhão. Professora do Departamento de Direito e do Mestrado em Direito e Instituições do Sistema de Justiça da Universidade Federal do Maranhão. Coordenadora do Núcleo de Estudos em Direito Sanitário (NEDISA/UFMA). Professora e Pesquisadora da Universidade Ceuma. Professora do IMEC. Membro Convidado da Rede Ibero-Americana de Direito Sanitário. Presidente da Comissão de Bioética e Biodireito do Conselho Seccional da OAB/MA. Tem experiência na área de Direito, com ênfase em Sociologia do Direito, Direito Constitucional e Direito Administrativo, atuando principalmente nos seguintes temas: direito sanitário, propriedade intelectual, inovação e políticas públicas.
} 


\section{INTRODUÇÃO}

A história do Judiciário como Poder de Estado responsável pela resolução dos conflitos de interesses tem sua origem formal com as Constituições dos Estados Unidos e da França, sendo estas os pontos de referência para a presente exposição.

As Revoluções Liberais ocorridas nos Estados Unidos e na França no final do século XVIII marcaram o fim dos regimes absolutistas e a fundação dos Estados de Direito, assentados sobre as bases do primado da lei, da limitação e separação do poder político, da intervenção mínima na economia e da garantia de direitos individuais e políticos (CANOTILHO, 2003).

O Estado de Direito consagrou o pensamento liberal burguês baseado no controle e direção do poder político a partir do poder econômico (BONAVIDES, 2011), cuja força concentrou-se na estrutura industrial capitalista que estava a pleno vapor com a Revolução Industrial inglesa.

As ideias de limitação e separação de poderes associadas à ideia de garantia de direitos registrados em documento escrito foram fundamentais para a consolidação do constitucionalismo moderno, concebido por Canotilho (2003) como movimento de natureza jurídica, ideológica, política, filosófica e social que produziu as constituições ${ }^{3}$, instituindo "técnica específica de limitação do poder com fins garantísticos" (CANOTILHO, 2003, p. 51).

O constitucionalismo francês sustentou como bandeira de luta o combate aos abusos praticados pelo monarca e os privilégios conferidos ao clero e à nobreza, decorrentes da sociedade estamental. Já o constitucionalismo estadunidense preocupou-se em limitar os arbítrios do governo da maioria e não apenas do monarca, tomando como referência a experiência parlamentar inglesa que impôs pesadas taxações contra a vontade dos colonos durante a relação colônia metrópole.

As diferentes visões, embora influenciadas pelo mesmo pensamento de limitação do poder, deram origem a modelos constitucionais diferentes e a modos distintos de enxergar a separação de poderes, o que até hoje influencia grande parte dos países ocidentais. Nessa perspectiva, o Poder Judiciário foi concebido com conotações distintas, prestando-se a papéis

\footnotetext{
${ }^{3}$ Adotou-se o conceito de constituição de Canotilho que entende ser ordenação sistemática e racional da comunidade política através de um documento escrito no qual se declaram as liberdades e os direitos e se fixam os limites do poder político (Canotilho, 2003, p. 52).
} 


\section{EXERCÍCIO DA FUNÇÃO INSTRUMENTAL PELO PODER JUDICIÁRIO NOS ESTADOS LIBERAL E SOCIAL: BREVES ANOTAÇÕES}

diferentes nos sistemas francês e estadunidense.

$\mathrm{Na}$ França, o Judiciário destinou-se ao exercício único e exclusivo da função jurisdicional instrumental, especializando-se na resolução dos conflitos de interesses, por meio da aplicação da lei (ARANTES, 2007).

Nos Estados Unidos, além de exercer a função jurisdicional instrumental, o Judiciário também recebeu capacidade política consubstanciada na possibilidade de controlar os atos normativos dos demais Poderes (ARANTES, 2007).

Essa diferença consolidou-se na França com a Constituição de 1791 que trouxe previsão expressa de que os tribunais não tinham competência para suspender a execução das leis; e nos Estados Unidos com o controle de constitucionalidade das leis que, embora não previsto no texto da Constituição Americana, foi rapidamente desenvolvido como mecanismo de defesa da supremacia da Constituição no famoso caso Marbury v. Madison, em 1803, a partir de um conjunto de artigos produzidos pelos federalistas.

Assim, enquanto na França o Judiciário se desenvolveu com inexpressivo peso político porque a ideia de supremacia do Legislativo, bem como a profunda insegurança em relação à magistratura do Antigo Regime, não podia ter levado a uma valorização do Judiciário como poder de Estado (ARANTES, 2007), nos Estados Unidos o Judiciário nasceu e se desenvolveu como verdadeiro poder político e utilizou a função jurisdicional não apenas para a resolução de conflitos de interesses, mas para servir de balança de equilíbrio na relação dos Poderes com a Constituição e a sociedade.

A partir da segunda metade do século XX e da influência do ordenamento jurídico alemão que introduziu um sistema de controle de constitucionalidade centralizado num órgão de cúpula do Judiciário, Zaffaroni (1995) identificou uma terceira função que paulatinamente começou a ser exercida pelo Poder Judiciário, o autogoverno, fruto de um processo de enfrentamento caracterizado pelo confronto do Judiciário com a classe política e outros órgãos do poder soberano (SANTOS. 1996), resultando na sua autonomia financeira, administrativa e política.

Para Santos (1996), esse embate entre os Poderes, gerado pela crise de representação político-partidária e social, encadeou uma série de outras crises institucionais, que expôs a promiscuidade do poder econômico com o poder político, revelando as entranhas da corrupção e do crime organizado no âmbito dos poderes Legislativo, Executivo e no próprio Judiciário. 
Essa conjuntura política, segundo Santos (2011), carreou inúmeros conflitos ao Judiciário, os quais ensejaram a judicialização da política, caracterizada por duas faces: a dos julgamentos de crises interna corporis pela ausência de formação de consensos e de infrações criminais cometidas pelos agentes políticos no exercício ou não da função pública; e a de formulação de políticas públicas diante da apatia ou incapacidade dos poderes públicos em resolver os conflitos ou atender as demandas dos grupos sociais (SANTOS, 2011).

Embora as três funções exercidas pelo Judiciário sejam importantes para a consolidação e permanência da democracia (BOCHENECK, 2013) e tenham se expandido nos últimos anos, especialmente pelo combate à corrupção no âmbito dos Poderes e pela ampliação dos mecanismos de controle de constitucionalidade, a pesquisa destinou maior atenção à função instrumental, porquanto é esta que supostamente passa por uma crise de eficiência nos atuais Estados Democráticos de Direito, colocando em xeque a capacidade do Poder Judiciário de dar respostas tempestivas e adequadas aos conflitos de interesses.

A suposta crise da função instrumental está diretamente relacionada com a evolução do Estado moderno que nos seus vários modelos exigiu do Judiciário diversas posturas, sendo importante conhecê-las para melhor compreensão da problemática. Por essa razão, o artigo utiliza o método descritivo exploratório com revisão bibliográfica e sistemática, com realce à apropriação de conceitos, como: função instrumental, estado liberal e estado social. Busca uma reflexão das determinações dos conteúdos presentes na construção das funções dos poderes estatais, para posteriormente, analisar a constituição da função política do Poder Judiciário.

Deve-se ressaltar que ao longo da pesquisa procurou-se a superação de posturas metodológicas rígidas, demarcando a análise em diversas variáveis contextuais (jurídico, sociais, econômicas e políticas) a fỉm de evitar considerações maniqueístas e sem objetivação científica, de sorte a produzir uma investigação socialmente situada.

\section{A FUNÇÃO INSTRUMENTAL DO JUDICIÁRIO NO ESTADO LIBERAL}

Para falar da função instrumental do Poder Judiciário nos Estados Liberal e Social é preciso considerar a advertência feita por Bocheneck (2013) de que o contexto econômico é uma variável indissociável nesse processo. De fato, depois que a burguesia assumiu as rédeas do poder político o fator econômico tornou-se a ordem do dia na definição das políticas estatais, visto que o sistema capitalista implantado privilegiou a propriedade privada e a acumulação de 


\section{EXERCÍCIO DA FUNÇÃO INSTRUMENTAL PELO PODER JUDICIÁRIO NOS ESTADOS LIBERAL E SOCIAL: BREVES ANOTAÇÕES}

capital.

A burguesia, após a Revolução Francesa, deu início a seu projeto de dominação com medidas que combinavam um ambiente de plena liberdade econômica com um ambiente ideológico de pretensa igualdade social. Pelo primeiro, a burguesia expandiu a economia de mercado, a divisão de classes, a propriedade privada e a lucratividade. Pelo segundo, a burguesia alimentou o ideal de que todos os homens nasceram livres e iguais, permanecendo nesta condição (HUNT, 2009) por meio de normas gerais e abstratas que colocavam os homens em situação de semelhança, livres da tirania e da opressão (BONAVIDES, 2011).

Desse discurso defluiu a prática liberal burguesa do laissez faire que exigiu do Estado duas posturas: proteção contra violações da propriedade privada e ataques externos; e afastamento da regulação social e econômica. Essa nova configuração ideológica permitiu à burguesia assumir a condição de classe social dominante, a partir da manipulação da vontalé générale (ROUSSEAU, 2003), por meio do parlamento, recrutado pela técnica do sufrágio restrito, o que conferiu uniformidade e harmonia ao seu projeto: o individualismo e a propriedade privada (CANOTILHO, 2003).

As primeiras constituições francesas e a Declaração dos Direitos do Homem e do Cidadão refletiram a ideologia liberal burguesa, pois elevaram o Poder Legislativo à categoria de órgão da soberania popular e serviram como elementos de limitação do poder e garantia das liberdades civis e políticas do cidadão em face do Estado (BONAVIDES, 2012). Esses Documentos entrelaçaram o poder político ao poder jurídico, de sorte que o Estado passou a ser confundido com o próprio Direito (SILVA, 2004), materializado no primado da lei editada pelo parlamento.

Instalou-se o positivismo legalista que consagrou a onipotência da lei como único instrumento legítimo de manifestação da soberania popular e resumiu o direito ao conjunto de regras formalmente postas pelo Estado (CANOTILHO, 2003). Esse monismo jurídico repeliu qualquer forma de normatividade social e delegou ao Estado o monopólio da produção das leis e a resolução dos conflitos de interesses decorrentes da não observância destas normas (WOLKMER, 2001).

O Estado de Direito, caracterizado pelo império da lei, pelo estado mínimo e pelo estado limitado (CANOTILHO, 2003) subordinou as funções executiva e jurisdicional à vontade do legislador, de modo que o Executivo e o Judiciário ficaram submissos ao Legislativo, agindo apenas nas hipóteses de determinação ou autorização legal. Esse quadro 
institucional fomentou um Poder Judiciário reativo e mecânico, destinado a solucionar casos concretos no modelo da subsunção formal, com juízes limitados a pronunciar as palavras da lei, adequando fatos sociais às leis estabelecidas, sem qualquer referência social, ética ou política (SANTOS, 1985).

Com a chegada de Napoleão ao Poder Executivo na França, assinala Zaffaroni (1995) que o Poder Judiciário tornou-se completamente submisso ao governo, o qual avocou a responsabilidade pela nomeação dos juízes e hierarquizou a função instrumental à semelhança dos corpos dos exércitos militares, e ainda, a partir do Código Napoleônico converteu os magistrados em meros espectadores passivos em relação ao objeto em litígio, carentes de capacidade interpretativa, e imersos no aparato administrativo burocrático do Estado (BOCHENEK, 2013).

O legalismo exacerbado, fruto da corrente filosófica positivista, afastou o Direito da Justiça (DALLARI, 2007) e manteve o Judiciário equidistante do povo e alheio ao processo de corrosão social provocado pelo desenvolvimento vertiginoso da economia capitalista, contribuindo para seu inexpressivo peso político (BOCHENECK, 2013). A postura conservadora apegada ao formalismo legal, com linguagem hermética própria e ritos procedimentais ininteligíveis, criou um fosso em relação à sociedade, de sorte que o Judiciário ficou imobilizado ocupando um honroso lugar de isolamento social (DALLARI, 2007). O acesso à justiça restringiu-se ao direito formal do indivíduo de ter acesso ao Poder Judiciário para propor ou contestar uma ação, refletindo uma filosofia essencialmente individualista (CAPPLLETTI E GARTH, 2002).

Mesmo no modelo estadunidense, em que o papel político do Judiciário sempre esteve implícito na organização constitucional dos Poderes (DALLARI, 2007), houve neutralidade quando instado a reconfigurar a estrutura social norte americana do século XIX. O caso Plessy v. Fergusson, em que a Suprema Corte ratificou a segregação racial, é um exemplo claro do evidente sinal de conservadorismo social e político do Judiciário (FURMANN, 2014). Mas também serviu para reafirmar que o Judiciário nos Estados Unidos tinha voz no processo de construção dos valores sociais, ainda que para manter o status quo.

Nesse compasso, Tocqueville (2005), avaliando a democracia americana, registrou que a grande invenção do sistema estadunidense consistiu em reservar a decisão em casos de conflitos constitucionais a um corpo de magistrados com razoável independência funcional, o que tornou a magistratura mais controlada politicamente e mais ativa (BOCHENECK, 2013). 
O mesmo autor concluiu que os magistrados americanos assemelhavam-se à própria aristocracia europeia e assinalou que:

Por isso, encontramos, oculta no fundo da alma dos juristas, uma parte dos gostos e
dos hábitos da aristocracia. Como ela, têm um instintivo pendor para a ordem, um
amor natural pelas formas; assim como a aristocracia, concebem um grande desgosto
pelas ações da multidão e, secretamente, desprezam o governo do povo. (...) Na
América, não existem nobres nem literatura, e o povo desconfia dos ricos. Por isso,
os juristas constituem a classe política superior e a porção mais intelectual da
sociedade. (TOCQUEVILLE, 2005, p. 201-206).

Dessa forma, no século XIX, seja na Europa seja nos Estados Unidos, o cenário foi de exploração e abusos proporcionados pelo capitalismo industrial, e de indiferença do Estado com a degradação das condições de vida da maioria da população, consequência de um engenhoso processo ideológico que proporcionou segurança jurídica contra intervenções abusivas na esfera jurídico patrimonial dos cidadãos (CANOTILHO, 2003). O Judiciário manteve-se alheio a toda essa turbulência, indiferente a problemas de aptidão das pessoas para reconhecer seus direitos e defendê-los adequadamente (CAPPLLETTI E GARTH, 2002).

A abstenção do Estado das relações socioeconômicas, o predomínio da ideologia liberal burguesa de defesa da propriedade privada, acúmulo de riquezas e aviltamento da mão de obra dos trabalhadores e ainda a expansão industrial, mergulharam a sociedade numa grave crise no período de transição entre os séculos XIX e XX, impulsionada pelo racionalismo, legalismo, relativismo e individualismo, valores voltados para a liberdade criadora do indivíduo e não para uma organização comunitária (BONAVIDES, 2011).

Contra a selvageria do sistema capitalista, movimentos de operários começaram a se organizar nacionalmente a fim de defender reivindicações econômicas e políticas e promover reformas no sistema vigente, dando início às lutas políticas por justiça social. Diversos manifestos, a exemplo do Manifesto Comunista (1848) e da Encíclica Rerum Novarum (1891), denunciaram a situação de exploração e abusos cometidos nas fábricas e buscaram alternativas ao modelo capitalista burguês, sendo o mais expressivo o modelo socialista, que no século XX dividiu o mundo entre Capitalismo e Socialismo.

Esse processo em busca de reformas políticas, econômicas e sociais resultou, no começo do século $\mathrm{XX}$, na ampliação dos direitos civis e políticos, dentre os quais a universalização do sufrágio, que diminuiu as barreiras censitárias e permitiu o fortalecimento da democracia a partir da participação de maior espectro de pessoas no processo de escolha dos governantes, e no surgimento dos primeiros direitos sociais, cuja referência na Europa foi a Constituição de Weimar de 1919, que, segundo Zaffaroni (1995, p. 40), não passou de um 
“instrumento meramente político, no qual valia mais a sua essência que as palavras de suas normas particulares". Ainda no primeiro quartel do século XX surgiu o primeiro organismo internacional preocupado com a melhoria das condições de trabalho das pessoas, a Organização Internacional do Trabalho (OIT), e também foi nesse período que houve um processo de transformação do sistema capitalista influenciado pelo progresso tecnológico, consoante assinala Bresser-Pereira (2013).

Esse conjunto de transformações afetou diretamente o exercício das funções pelos órgãos do Estado que passaram a utilizar o modelo de administração burocrática, orientado pela ideia de profissionalização, carreira, hierarquia funcional, impessoalidade, formalismo, enfim, pelo modelo racional-legal (WEBER, 1979), em substituição ao modelo de administração patrimonial, baseado na dependência funcional e confusão do patrimônio público com o privado.

Para Weber (1979) o modelo burocrático proporcionava a forma mais racional de exercício da dominação, pois estava assentado na validade das leis e da competência funcional. Ele afastava as influências pessoais ou sentimentais que comprometiam o pleno funcionamento das organizações e a disciplina do serviço e ainda proporcionava previsibilidade e estabilidade, criando ambientes adequados para hierarquia, cooperação, competência técnica e redução de custos (BARBOSA E QUINTANEIRO, 2002).

Este modelo contribuiu para a expansão do aparelho burocrático do Estado e passou a regular de forma intensiva e extensiva as relações sociais, por meio de uma estrutura especializada, segundo critérios de racionalidade baseados em normas gerais e abstratas aplicadas a casos concretos por via de processos lógicos controláveis (SANTOS, 1985). Serviu também de referência para a organização do Poder Judiciário que, preocupado com a eficiência das funções e eficácia social do direito, passou por um processo de estratificação e especialização de funções, a fim de que o corpo técnico pudesse oferecer um serviço de qualidade (SANTOS, 1988).

Porém, como nenhum sistema é perfeito, Weber (1979) identificou problemas que possivelmente poderiam levar à ineficiência do modelo burocrático, denominando essas anomalias de disfunções burocráticas. Essas disfunções foram fruto da rigidez do sistema frente às mudanças no contexto da sociedade e/ou da desconsideração de rotinas informais criadas no exercício da atividade burocrática (CARVALHO, 2010). Como exemplo destas disfunções Damasceno (2011) destaca: o exagerado apego aos regulamentos, o excesso de formalismo, a 
divisão sistemática do trabalho; a impessoalidade exagerada no atendimento e a rígida hierarquização da autoridade burocrática.

De fato, estas disfunções começaram a produzir problemas para as organizações estatais burocráticas, visto que seus agentes tornaram-se escravos das normas e dos procedimentos, comprometeram a agilidade dos processos em função da necessidade de registro escrito de todas as comunicações, limitaram suas capacidades de desempenho por não conhecerem a atividade por inteiro, criaram distinções no atendimento em razão de posturas inflexíveis e atrapalharam o processo decisório por estarem inibidos de praticar qualquer comportamento fora dos padrões estabelecidos (DAMASCENO, 2011).

Em contrapartida, no mesmo período, houve grande desenvolvimento da Sociologia Jurídica, que prestou inegáveis serviços ao Direito mediante o uso de métodos e técnicas de investigação empírica, que conduziram a ciência jurídica a ser investigada sob a ótica dos fenômenos sociais, consolidando a percepção de que o Estado não era a única fonte de produção do direito (SANTOS, 2010), contrariando a visão jurídica monista. A sociologia jurídica, a partir da escola do Direito Vivo, contribuiu para fundar os alicerces das futuras propostas de um direito alternativo ao direito estatal. Inúmeras pesquisas foram realizadas com o propósito de demonstrar que os conflitos sociais poderiam ser resolvidos sem a presença estatal formal, estavam lançadas as bases do pluralismo jurídico, representadas por Kantorowicz e Ehrlich na Europa, Posner nos Estados Unidos e Santos na América Latina.

O novo enfoque deu ensejo à convivência simultânea de duas perspectivas de compreensão do direito. A primeira baseada no direito formalmente vigente, que encontrou no positivismo extremado, estático, calcado exclusivamente na lei, sua razão de ser. A segunda fundada na normatividade ascendente das relações sociais, que teve por esteio o positivismo moderado, dinâmico, influenciável e mutável (SANTOS, 1985). As duas visões alicerçaram o processo de transição que resultou na visão sociológica centrada nas dimensões processual, institucional e organizacional do direito, em contraponto à visão normativista baseada nos enunciados abstratos da lei (SANTOS, 1985). Tais precedentes levaram o direito a ser discutido sobre as premissas do direito socialmente eficaz e do direito formalmente vigente, que permearam todos os campos teóricos de debate envolvendo a ciência jurídica.

O modelo alternativo da sociologia jurídica também produziu reflexos na elaboração da jurisprudência dos tribunais porquanto engendrou um processo de transição da jurisprudência dos conceitos, limitada pela subsunção lógico-formal da matéria de fato aos 
conceitos jurídicos, para a jurisprudência dos interesses, que passou a valorar a vida e considerar a realidade social para a aplicação do Direito (LARENZ, 1997).

O processo de transformação social já impulsionado pelo agravamento das desigualdades sociais e econômicas no final do século XIX foi acelerado com a destruição da Europa provocada pela Primeira Guerra Mundial, a recessão provocada pela Crise de 1929 nos Estados Unidos e a devastação mundial produzida pela Segunda Grande Guerra. Estes eventos serviram para demonstrar as fragilidades do sistema liberal burguês e a necessidade de profundas mudanças sociais, políticas e econômicas em busca de um novo estilo de vida.

\section{A FUNÇÃO INSTRUMENTAL DO JUDICIÁRIO NO ESTADO SOCIAL}

Os horrores provocados pela Segunda Guerra mundial deixaram claro que não bastava um conjunto de leis para restringir os poderes do Estado contra o cidadão e garantir igualdade formal entre os indivíduos, havia a necessidade de considerar o homem pelo simples fato de ser homem, dotado das mesmas qualidades e sem distinções de qualquer natureza. Por essa razão as relações internacionais foram reorganizadas com base no respeito incondicional à dignidade humana (COMPARATO, 2016), tendo na Organização das Nações Unidas sua pedra de toque, visto que nasceu vocacionada a lutar pela dignidade humana em todo globo terrestre.

O Estado de bem estar social emergiu como produto desse conjunto de transformações e teve por objetivo atender grupos sociais inteiros por meio de programas governamentais que proporcionassem mínima qualidade de vida para as pessoas, ou seja, os poderes públicos passaram a intervir no livre jogo do mercado para proporcionar justiça social através de programas que atendessem as necessidades coletivas e não apenas as individuais (COMPARATO, 2016).

A partir daí, o Estado começou a consolidar medidas intervencionistas tanto no mercado quanto na sociedade a fim de melhorar a condição de vida das pessoas, de modo que em pouco tempo estenderam a rede dos serviços sociais, instituíram carga fiscal fortemente progressiva e se preocuparam com a sustentação do empregado e com a manutenção do desempregado (BOBBIO, MATTEUCCI E PASQUINO, 1999, p. 418).

No novo modelo o Estado se responsabilizou pela implementação das políticas públicas sociais, destacando-se o Poder Executivo, órgão responsável pela administração dos recursos sociais e econômicos, pelo planejamento e formulação dos programas de governo. $\mathrm{O}$ 


\section{EXERCÍCIO DA FUNÇÃO INSTRUMENTAL PELO PODER JUDICIÁRIO NOS ESTADOS LIBERAL E SOCIAL: BREVES ANOTAÇÕES}

Estado investiu em obras de infraestrutura e na expansão da administração pública, criando uma enorme estrutura burocrática, que utilizou mais intensamente o modelo burocrático de Weber (1979) e as suas disfuncionalidades.

O revigoramento do Estado, além de colocar em evidência o Poder Executivo, revitalizou os Poderes Legislativo e Judiciário. O Legislativo ao criar leis regulamentando inúmeros setores da vida social tornou jurídica a realidade fenomênica, em especial os direitos sociais previstos nas constituições. O Judiciário, ao ser chamado para garantir os direitos sociais consagrados nas legislações, começou a tratar a justiça distributiva como questão de direito e não apenas como questão de política, fato que exigiu nova postura no cenário das responsabilidades (SANTOS, 1995), abandonando a característica reativa e de indiferença social para assumir postura prospectiva de efetivação dos direitos prometidos pelo Estado.

Nessa linha, o significado de acesso à justiça não estava mais resumido à possibilidade de ajuizar demandas na justiça, englobava também à capacidade do Judiciário em trabalhar pelo sucesso dos programas estatais de bem-estar social, por isso Bocheneck (2013, p. 48) assinala que

O judiciário deixa de apenas julgar no sentido de estabelecer o certo e o errado com base estritamente na lei, mas, sobretudo, passa a examinar se o exercício do poder de legislar conduz à concretização dos resultados objetivados, ou seja, por meio da responsabilidade prospectiva, o Judiciário, de certa forma, se repolitiza e desneutraliza.

Interessante notar que a atuação mais incisiva do Judiciário ocorreu com a superação do discurso de que o direito, enquanto instrumento de dominação, estava à disposição apenas da burguesia. Sob esse ponto Santos (2010) registrou que os movimentos sociais perceberam que o direito, como instrumento hegemônico, poderia ser utilizado para fins não hegemônicos. A partir das ambiguidades conceituais e das brechas proporcionadas pelo próprio sistema jurídico, os movimentos sociais passaram a utilizá-lo como uma arma na defesa de seus interesses (SANTOS, 2011).

O Judiciário passou então a instância de implementação dos direitos sociais (ARANTES, 2007), fugindo ao padrão do Estado Liberal, que se contentava com a mera resolução de conflitos individuais. O desafio proposto ao Judiciário consistiu em dar efetividade aos direitos sociais constitucionalizados frente a uma estrutura institucional criada para atender outra espécie de demanda (demandas individuais) e ainda carente de recursos financeiros e humanos. Esse desafio tornou-se ainda maior com o surgimento de um novo conjunto de direitos difusos e indivisíveis, que atingiram número indeterminado de pessoas e abriram 
espaços políticos de participação direta dos indivíduos e da sociedade na articulação e deliberação dos planos estratégicos coletivos.

O Poder Judiciário foi afetado ainda pelo novo modelo de Constituição adotado nos Estados Sociais após a Segunda Guerra mundial, baseado em princípios de conteúdo aberto e cláusulas gerais, o que favoreceu a leitura moral das constituições e os novos esquemas de interpretação das normas jurídicas supremas (SARMENTO, 2004). Esse fenômeno, apelidado de neoconstitucionalismo, transformou as fontes formais do Direito ${ }^{4}$ na medida em que alterou a natureza jurídica dos princípios, mudou os esquemas de elaboração das leis e reconfigurou o papel da jurisprudência. O neoconstitucionalismo criou o ambiente propício para que as constituições, definitivamente, assumissem o papel de norma jurídica fundamental (KELSEN, 1998), tornando-se a referência do poder político nos estados democráticos e a "lente através da qual se leem e se interpretam todas as normas infraconstitucionais" (BARROSO, 2006, p. 4).

Os princípios tornaram-se espécies de normas jurídicas dotadas de força normativa que serviram de fonte autônoma de direitos e de vetor orientativo para a elaboração, interpretação e aplicação das normas jurídicas. Passaram a expressar os ideais de justiça de uma comunidade e condensaram numa mesma unidade positiva os aspectos axiológicos e deontológicos da normatividade jurídica (CUNHA, 2006). Espelharam a ideologia da sociedade, seus postulados básicos, seus fins, proporcionando unidade e harmonia ao sistema, integrando suas diferentes partes e atenuando as tensões normativas (BARROSO, 2002). Por serem plásticos começaram a conferir maior flexibilidade à Constituição, permitindo sua adaptação às mudanças ocorridas na sociedade (SARMENTO, 2009).

A nova natureza jurídica dos princípios contribuiu para a mudança no processo de elaboração das leis. Abandonou-se o sistema tradicional baseado em hipóteses claras e consequentes normativos definidos e adotou-se a técnica legislativa das cláusulas gerais, pela qual as normas jurídicas foram construídas no esquema de hipóteses abertas com consequentes normativos abertos, a fim de tornar possível a adequação dos institutos jurídicos às mudanças nas relações sociais

Nesse processo, a produção jurídica dos tribunais ganhou novos contornos visto que a jurisprudência passou a colmatar os conteúdos dos princípios e das cláusulas gerais. Abriu-se

\footnotetext{
${ }^{4}$ Compreendeu-se por fontes formais o conjunto de atos jurídicos dotados de força normativa e de eficácia vinculante direta sobre a conduta dos sujeitos e dos órgãos públicos incumbidos oficialmente da solução de controvérsias (RAMOS, 2013, p. 104)
} 
novo caminho na seara da interpretação, exigindo-se maior engajamento dos intérpretes na construção das categorias jurídicas, a fim de proporcionar segurança nas decisões judiciais e efetividade dos direitos fundamentais. Passou-se então da jurisprudência dos interesses para a jurisprudência dos valores (LARENZ, 1997).

O fenômeno de uma comunidade global, com valores universais, denominado globalização, aproximou os dois maiores sistemas jurídicos culturais do Ocidente - os sistemas da Commow Law e Civil Law -, de sorte que passaram a interagir e influenciar-se mutuamente, o que também fortaleceu a jurisprudência nos países de tradição legal, que lançaram mão das técnicas do precedente e das súmulas.

Todas as transformações sociais, políticas e jurídicas afetaram a função originária de instância de resolução de conflitos do Judiciário, historicamente orientada pelo excessivo apego às fórmulas processuais, de sorte que fazia todo sentido um conjunto de mudanças na estrutura institucional e cultural deste Poder para comportar as demandas político-sociais que passaram por um período de grande expansão. Foi nesse período que os países desenvolvidos promoveram uma série de reformas no Poder Judiciário que, em linhas gerais, perpassaram pela informalização da justiça, pelo reaparelhamento dos tribunais em recursos humanos e infraestrutura, pela criação de juízos especiais para pequenas causas, pela proliferação de mecanismos alternativos de resolução de conflitos e por mudanças processuais (Santos, 1996).

Contudo, a crise vivenciada pelo Estado Social na década de setenta em razão da falta de condições financeiras para arcar com as altas despesas provenientes da implementação dos direitos sociais e pelos elevados níveis de desperdício e ineficiência provocados pela burocracia (BOCHENEK, 2013), reduziu o processo de reformas que vinha experimentando o Judiciário. Por outro lado, foi essa mesma crise que deu ensejo ao fortalecimento da ideologia neoliberal capitalista, que, assentada sobre as regras de mercado e contratos privados, exigiu um judiciário rápido, eficaz e independente, destinado a garantir o cumprimento e a estabilidade dos negócios jurídicos (SANTOS, 2010), o que contribuiu para a retomada das reformas judiciais já em andamento.

O modelo neoliberal estimulou a privatização de vários serviços públicos, a desregulamentação da economia, a diminuição dos gastos sociais e a redução do déficit público (ARANTES, 2007). O propósito foi diminuir a burocracia estatal e implantar um modelo gerencial de administração pública, baseado na lógica do custo benefício e na produção quantitativa. Contribuíram para a difusão desse modelo, cuja ideologia orientou as reformas 
institucionais nos países ocidentais capitalistas a partir de então, o descrédito da representação política, a corrupção e o crescente nível de desigualdade social (BOCHENEK, 2013). Estes fatores, como já apontado, foram determinantes também para a imersão do Judiciário no campo político.

Essa nova perspectiva deu ensejo a um cenário político econômico de contrários, orientado pelos vetores da igualdade material prometida pelo Estado Social versus liberdade de mercado do modelo neoliberal burguês, que terminou por envolver o Judiciário no processo de equacionamento da igualdade jurídico formal com as desigualdades socioeconômicas (SANTOS, 2011). Nesse cenário dúbio, o Judiciário, ao invés de se retrair com o desmantelo do Estado social, foi cada vez mais exigido por amplos setores da sociedade e do próprio Estado, o que contribuiu para consolidar o papel político e social deste Poder e para o aumento dos conflitos de interesses entre as mais diversas representações sociais.

A intensa procura pela função instrumental do Judiciário para efetivar a legislação social expandiu o número de demandas nas instâncias judiciais, esperando-se que o Poder Judiciário pudesse resolver os problemas que o sistema político não conseguiu solucionar (SANTOS, 2010). Todavia, a estrutura limitada do Poder Judiciário, seja pelo contingenciamento orçamentário, seja pela pouca capacidade operativa, não comportou o volume de ações demandadas, produzindo problemas no oferecimento de respostas efetivas aos anseios da sociedade. Desse fenômeno decorreu a maior exposição das dificuldades de acesso ao sistema de justiça, de eficiência da função instrumental e também os diagnósticos mais sistemáticos sobre os limites e novas possibilidades de acesso à justiça (ARANTES, 2007).

A partir dessa realidade, iniciou-se um conjunto de investigações sobre os problemas de acesso à Justiça, tendo como grande marco a obra Acesso à Justiça de Cappelletti e Garth (2002), publicada originalmente em 1978. Essa obra reuniu informações sobre os principais problemas de acesso à justiça em várias partes do mundo e ainda apresentou uma série de experiências que foram adotadas pelos países para combater os obstáculos e facilitar o acesso a esse direito fundamental.

Cappelletti e Garth (2002) propuseram, como práticas de enfrentamento dos obstáculos ao acesso à justiça, um conjunto de três soluções pelas quais progressivamente foram sendo removidas as barreiras do acesso à justiça. Essas soluções foram produto da análise de diversos modelos utilizados em vários países do mundo, os quais foram condensados no relatório denominado Projeto Florença. 
Nesse relatório, os autores apresentaram as famigeradas ondas de acesso à justiça, assim resumidas: assistência judiciária gratuita (primeira onda); representação jurídica para os interesses difusos (segunda onda); e enfoque do acesso à justiça (terceira onda), cuja atenção se concentrou no "conjunto geral de instituições e mecanismos, pessoas e procedimentos utilizados para processar e mesmo prevenir disputas nas sociedades modernas" (CAPPELLETTI E GARTH, 2002, p. 68).

Estas ondas foram responsáveis por grandes avanços no acesso à justiça (NUNES E TEIXEIRA, 2013), pois proporcionaram a criação de órgãos responsáveis pela defesa dos hipossuficientes e adequações no sistema judicial para comportar as demandas difusas e coletivas. Mas, foi a terceira onda que propiciou um estudo crítico que contemplou a reforma de todo o aparelho judicial, sem descurar de outros fatores diretamente relacionados com essas reformas, especialmente o complexo maquinário já existente para a solução de litígios. Nela concentrou-se um conjunto de esforços empíricos e teóricos para permitir ao sistema a efetivação dos direitos (CAPPELLETTI E GARTH, 2002).

Na terceira onda de acesso à justiça priorizou-se a criação de alternativas ao sistema judiciário regular e sugeriu-se a reforma dos procedimentos judiciais em geral, prestigiando a oralidade na produção dos atos judiciais, a concentração de atos em uma única audiência e a redução das custas judiciais em geral. As propostas de reforma na terceira onda tiveram a intenção de solucionar os litígios de maneira informal, rápida e barata (CAPPELLETTI E GARTH, 2002).

Para Santos (2011) a terceira onda de acesso à justiça procurou expandir a concepção clássica de resolução judicial de litígios desenvolvendo um conceito amplo de justiça no qual o Poder Judiciário passou a fazer parte de um conjunto integrado de meios de resolução de conflitos, denominado de ADR (Alternative Dispute Resolution).

Enquanto nas décadas de 80 e 90 essas tendências foram utilizadas nos países desenvolvidos para estabilizar as expectativas das pessoas e potencializar a cidadania, nos países menos desenvolvidos constituíram condição para que pudessem participar do mercado econômico internacional. Por essa razão, o relatório de Cappelletti e Garth foi estrategicamente utilizado pelas agências de fomento das economias em desenvolvimento para promover as reformas do Poder Judiciário, especialmente às relacionadas à terceira onda de acesso à justiça.

Novamente o fator econômico tornou-se essencial na definição das políticas estatais só que desta vez de forma globalizada e com os discursos de maior interação entre os setores 
públicos e privados e de estabilidade das instituições para garantir o pleno desenvolvimento econômico dos países. Não por acaso a agência internacional que utilizou esse discurso foi o Grupo Banco Mundial, justamente para condicionar a liberação de financiamentos à implantação dos modelos propostos.

O Banco Mundial, a partir dessa realidade, estabeleceu um padrão para as reformas dos judiciários nacionais, procurando incorporá-lo aos sistemas jurídicos internos de forma indireta, pela ação "meramente educativa" (CANDEAS, 2004, p. 22). Esse padrão se baseou nos seguintes valores: previsibilidade das decisões, independência, eficiência, transparência, credibilidade, combate à corrupção, proteção à propriedade privada, respeito aos contratos e acessibilidade - métodos alternativos de solução de controvérsias (CANDEAS, 2004).

A partir destas reformas, o Judiciário passou a compartilhar sua função instrumental como os meios alternativos de resolução de conflitos e para não perder poder passou a incorporá-los na sua política estratégica institucional, espalhando-se pelo mundo sob o discurso de facilitação do acesso à justiça e diminuição da demanda processual.

\section{CONSIDERAÇÕES FINAIS}

Analisou-se o exercício da função instrumental pelo Poder Judiciário nos Estado Liberal e Social com o objetivo de demonstrar que, embora tenha ocorrido mudança de essência nesta função nos modelos de Estado, não houve alteração de estrutura e de cultura judiciária, produzindo sérios problemas de eficiência para atender as novas demandas sociais (SANTOS, PEDROSO, FERREIRA, 1996).

Nessa conjuntura ganhou destaque a teoria de Cappelletti e Garth sobre as ondas de acesso à justiça, que, após analisar os problemas de acesso à justiça em vários países do mundo, propôs um conjunto de reformas no sistema jurídico, destinadas a torná-lo mais simples, econômico e eficiente e a criar meios alternativos de resolução de conflitos. Essa teoria espalhou-se rapidamente pelo mundo como solução para os problemas de morosidade e burocracia do Poder Judiciário, sendo estrategicamente utilizada pelo Banco Mundial para determinar as reformas no Poder Judiciário brasileiro (MELO FILHO, 2003).

Pode-se afirmar que o Judiciário foi o poder que mais se reconfigurou nos últimos 
duzentos anos (SANTOS, 1990), exercendo outras funções para muito além da função jurisdicional de resolução dos conflitos de interesses, marca característica da jurisdição, assumindo a função político-institucional do controle de constitucionalidade das leis em sentido amplo e a função de autogoverno nas constituições do pós-guerra (ZAFFARONI, 1995).

Não obstante, nenhuma das funções exercidas pelo Judiciário apresenta, ainda hoje, clareza quanto a sua extensão e profundidade, tornando-se obtusa a discussão sobre os rumos e reformas estruturais incidentes sobre este poder. Este é um sério problema que inclusive tem afetado os outros Poderes do Estado, instalando-se um período de rivalidade entre eles, caracterizado pelas práticas ativistas, fenômeno que retrata a invasão das funções de um poder por outro (RAMOS, 2010), demandando a reformulação dos papéis conferidos aos três Poderes.

\section{Referências}

ARANTES, Rogério Bastos. Judiciário e política no Brasil. São Paulo: Editora Sumaré, 1997.

ARANTES, Rogério Bastos. Judiciário: entre a Justiça e a Política. In: Avelar, L.; Cintra, A.

O. (Org.). Sistema político brasileiro: uma introdução. 2. ed. Rio de Janeiro: Konrad-

Adenauer- Stiftung; São Paulo: Unesp, 2007.

BARROSO, Luís Roberto. Fundamentos teóricos e filosóficos do novo Direito

Constitucional Brasileiro. Direito e Democracia. Canoas. Vol. 03, $\mathrm{n}^{\mathrm{o}} 2,2^{\circ}$ sem. 2002, p. 345383.

$\overline{\text { Janeiro: Renovar, } 2009 .}$

O direito constitucional e a efetividade de suas normas. $9^{\text {a }} \mathrm{Ed}$. Rio de

BOBBIO, Norberto; MATTEUCCI, Nicola; PASQUINO, Gianfranco. Dicionário de política. Trad. Carmen C, Varriale et al.; coord. trad. João Ferreira; rev. geral João Ferreira e Luis Guerreiro Pinto Cacais. Brasília: Editora Universidade de Brasília, 1 ed., 1999.

BOCHENEK, Antônio César. A interação entre os tribunais e democracia por meio do acesso aos direitos e à justiça: análise de experiências dos juizados especiais federais cíveis brasileiros/Antônio César Bochenek. - Brasília: CJF, 2013

BONAVIDES, Paulo. Do estado liberal ao estado social. 10. ed. São Paulo: Malheiros, 2011 BRESSER PEREIRA, Luiz Carlos. Da administração pública burocrática à gerencial. Revista do Serviço Público, v. 47, n. 1, jan./abr. 1996.

BRESSER-PEREIRA, Luiz Carlos. Gestão do setor público: estratégia e estrutura para um novo Estado: In: BRESSER-PEREIRA, L. C; SPINK, P. (Org.). Reforma do Estado e 
Administração Pública Gerencial. 7. ed. Rio de Janeiro: Editora FGV, 2006. BRESSER PEREIRA, Luiz Carlos. Revolução capitalista e formação do estado-nação. Texto para discussão 326. FGV. Agosto de 2013. Disponível em http://www.eesp.fgv.br. Acesso em 15 de nov. 2015

BULOS, Uadi Lâmmego. Curso Direito Constitucional. 6. ed. rev. e atual. São Paulo: Saraiva, 2011.

CANDEAS, Ana Paula Lucena Silva. Os Valores recomendados pelo Banco Mundial para os Judiciários nacional. Revista da Associação dos Magistrados Brasileiros: Cidadania e Justiça, [Brasília], n. 13, p. 21-43, 2004. Disponível em:

$<$ http://www.amb.com.br/docs/publicacoes/outros/revista_cj_n7.pdf $>$. Acesso em: 30 mar. 2012.

CANOTINLHO, Joaquim José Gomes. Direito Constitucional e Teoria da Constituição. 7. ed. Coimbra: Almedina, 2003.

CAPPELLETTI, Mauro; GARTH, Bryant. Acesso à Justiça. Tradução de Ellen Gracie Northfleet. Porto Alegre: Sergio Antonio Fabris, 2002.

CARVALHO, Débora. As disfunções da burocracia transformam-se na própria

''burocracia', 2010. Disponível em: <http://www.administradores.com.

br/informe-se/artigos/as-disfuncoes-da-burocracia-transformam-se-

na-propria-burocracia/44412/>. Acesso em: 29 nov. 2015.

COMPARATO, Fábio Konder. A afirmação histórica dos direitos humanos. São

Paulo: Saraiva, 2016.

CUNHA, José Ricardo. Sistema aberto e princípios na ordem jurídica e na metódica constitucional. In: Os princípios da Constituição Federal de 1988. $2^{\mathrm{a}}$ Ed. rev. amp. Rio de Janeiro: Lúmen Juris, 2006.

DALLARI, Dalmo de Abreu. O poder dos juízes. 3. ed. rev. São Paulo: Saraiva, 2007.

DALLARI, Dalmo de Abreu. Elementos da teoria geral do Estado. São Paulo: Saraiva, 2007.

FALCÃO, Joaquim de Arruda. O futuro é plural: administração de justiça no Brasil. Revista USP, São Paulo, n.74, p. 22-35, junho/agosto 2007.

Novo produto do poder judiciário. Disponível em:

«http://niajajuris.org.br/index. php?option $=$ com_content\&view $=$ article\&id=315:novoproduto- do-poder-judiciario\&catid=21:ultimasnoticias\&Itemid=27». Acesso em 9.abr. 2016. FUHRMANN, Italo Roberto. Judicialização dos direitos sociais e o direito à saúde: por uma reconstrução do objeto do direito à saúde no direito brasileiro. Brasília: Consulex, 2014. KELSEN, Hans. Teoria Pura do Direito (Trad. João Batista Machado). 6 a Ed. São Paulo: Martins Fontes, 1998.

LARENZ, Karl. Metodologia do Direito. Trad. José Lamego. 3. ed. Lisboa: Fundação Calouste Gulbenkian, 1997.

MELLO, Leonel Itaussu Almeida. Os clássicos da política, 1 / Francisco C.Weffort, organizador. 14. ed. - São Paulo: Ática, 201: Conteúdo: v.1. Maquiavel, Hobbes, Lock e, Montesquieu, Rousseau,"Os Federalista"

MELO FILHO, Hugo Cavalcanti. A reforma do Poder Judiciário Brasileiro: motivações, quadro atual e perspectivas. Revista CEJ, Brasília, n. 1, p. 79-86, abr./jun. 2003. Disponível em: $<$ http://www2.cjf.jus.br/ojs2/index.php/revcej/article/viewFile/551/731>. Acesso em: 30 nov. 2014.

MORRIS, Clarence (org.). Os Grandes filósofos do direito. São Paulo: Martins Fontes, 2002.

NUNES, Dierle; TEIXEIRA, Ludmila. Acesso à justiça democrático. 1. Ed.- Brasília: 
Gazeta Jurídica, 2013.

Perry, C. 1998, "Processes of a case study methodology for postgraduate research in marketing" The European Journal of Marketing, vol. 32, nos. 9/10, pp. 785-802

PIFERRER, Ana et al. La mediación: resolución alternativa de conflictos. Revista Economist and Jurist, 1999.

QUINTANEIRO, Tania; BARBOSA, Maria Ligia de Oliveira; OLIVEIRA, Márcia Gardênia de. Um toque de clássicos: Marx, Durkheim e Weber. 2. ed., rev. e ampl Belo Horizonte, MG: Ed. UFMG, 2002.

RAMOS, Elival da Silva. Ativismo judicial: parâmetros dogmáticos. São Paulo: Saraiva, 2010.

SANTOS, Boaventura de Souza. O direito e a comunidade: as transformações recentes da natureza do poder do Estado nos países capitalista avançados. Revista Crítica de Ciências Sociais, n. 10, 1982.

. Introdução à Sociologia da Administração judiciária. In: Revista de

Processo no 37, pp. 121-139. São Paulo, 1985.

. O Estado e o Direito na Transição Pós-Moderna: para um Novo

Senso Comum sobre o Poder e o Direito. In: Revista Crítica de Ciências Sociais, $\mathrm{n}^{\circ} 30$.

Coimbra, 1990.

Paulo: Cortez, 2010.

. Pela mão de Alice: o social e o político na pós-modernidade. 13. ed. São

Para uma revolução democrática da justiça. 3. ed. rev.

SARMENTO, Daniel. Direitos Fundamentais e Relações Privadas. Rio de Janeiro: Lúmen Juris, 2004.

SARMENTO, Daniel (coord.). Filosofia e Teoria Constitucional Contemporânea. Texto: O

Neoconstitucionalismo no Brasil: Risco e possibilidades. Rio de Janeiro: Lúmen Juris, 2009.

SILVA, José Afonso. Curso de Direito Constitucional Positivo. São Paulo: Malheiros, 2004. TOCQUEVILlE, Alexis. Democracia na América. Trad. Eduardo Brandão. São Paulo:

Martins Fontes, 2005

WEBER, Max. A ciência como vocação. In: GERTH, HANS; MILLS, Wright. Max Weber. Ensaios de Sociologia. Tradução de Waltensir Dutra. Rio de Janeiro, 1979.

WEBER, Max. A política como vocação. In: GERTH, HANS; MILLS, Wright. Max Weber. Ensaios de Sociologia. Tradução de Waltensir Dutra. Rio de Janeiro, 1979.

WEBER, Max. Economia e sociedade: fundamentos da sociologia compreensiva. Tradução de Regis Barbosa e Karen Elsabe Barbosa. Brasília: Universidade de Brasília, 1999.

WOLKMER, Antônio Carlos. Pluralismo Jurídico. $2^{\circ}$ Ed. São Paulo: Ed. Alfa Ômega, 2001. ZAFFARONI, Eugênio Raul. Poder judiciário: crise, acertos e desacertos. Trad. Juarez Tavares. São Paulo: Revista dos Tribunais, 1995. 